\title{
Bezpośrednia diagnostyka kompozytowych elementów lotniczych z wykorzystaniem struktur inteligentnych
}

\author{
Self-diagnostics of composite aerospace structures \\ with use of inteligent materials
}

\section{Streszczenie}

Zastosowanie fal sprężystych wzbudzonych w badanym elemencie za pomocą umieszczonej na nim sieci przetworników piezoelektrycznych jest jednym z obiecujących kierunków rozwoju technologii bezpośredniej diagnostyki struktur lotniczych (SHM). Możliwości systemów SHM są związane z dwoma różnymi ścieżkami rozwoju tej technologii, tj. zastosowanych rozwiązań technicznych, np. rodzaju przetworników PZT czy aparatury pomiarowej oraz metod analizy sygnału rejestrowanego przez przetworniki. Do pierwszej gałęzi rozwoju systemów SHM należy m.in. dobór optymalnego rodzaju przetworników PZT do danego zagadnienia oraz sposób ich związania z monitorowaną strukturą. W przypadku kompozytów, oprócz związania przetworników z badaną powierzchnią, możliwe jest również ich wbudowanie w wewnętrzną strukturę materiału. W artykule zaprezentowano przykład wykorzystania przetworników PZT wbudowanych w strukturę kompozytową do detekcji uszkodzeń udarowych BVID. Zaprezentowano algorytm lokalizacji uszkodzeń BVID oraz wyniki badań laboratoryjnych weryfikujących zaproponowane metody.

Słowa kluczowe: przetworniki PZT, detekcja i lokalizacja uszkodzeń udarowych, materiały kompozytowe

\section{Abstract}

Application of guided waves excited by a network of PZT transducers integrated with a given structure is one of the promising approaches to Structural Health Monitoring (SHM). The per-formance of SHM system based on PZT network is rooted in two distinct areas of the techno-logy development, that is: the hardware and the signal analysis. The first includes is the type of transducers used to built a network and the way of their integration with a monitored structure. For composites, beside the possibility of the transducers attachment to a surface of an element, also embedding of PZTs into their internal structure is available. In the article Barely Visible Impact Damage (BVID) detection capabilitiy of the embedded PZT transducers is presented. An algorithm of damage localization is also proposed and verified in laboratory tests.

Keywords: PZT transducers, impact damage detection and localization, composite materials

\section{Wstęp}

Stosowane obecnie systemy eksploatacji statków powietrznych mogą w przyszłości okazać się ekonomicznie nieefektywne jak również niewystarczające z punktu widzenia bezpieczeństwa. Podstawą bezpiecznej eksploatacji statków powietrznych w wymiarze zapewnienia integralności struktury są m.in. programy badań nieniszczących (ang. non-destructive testing - NDT) opracowywane dla konkretnych modeli [1]. Ich zakres oraz częstotliwość wykonywania zależy od zakładanego profilu eksploatacji i stopnia koncentracji naprężeń w elementach strukturalnych, trwałości zmęczeniowej użytych materiałów jak również możliwości stosowanych metod NDT. Rzeczywiste widmo obciążeń danego egzemplarza statku powietrznego może jednakże odbiegać od założeń stosowanych na etapie jego projektowania lub może on być długotrwale eksploatowany w warunkach sprzyjających przyspieszonej degradacji struktury, natomiast czułość metod NDT ocenia się w warunkach laboratoryjnych w ramach tzw. badań PoD (ang. Probability of Detection) [2], co nie pozwala na odwzorowanie rzeczywistego badania, a zwłaszcza minimalizuje wpływ czynnika ludzkiego. Od przeszło dwóch dekad prowadzone są badania nad zaimplementowaniem metod NDT w postaci zintegrowanych ze strukturą statków powietrznych systemów SHM (ang. Structural Health Monitoring), umożliwiających

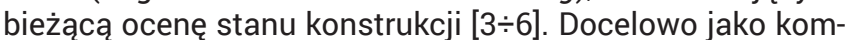
ponenty systemów HUMS (ang. Health and Usage Monitoring

Dr inż. Krzysztof Dragan, mgr Michał Dziendzikowski, dr hab. inż. Andrzej Leski - Instytut Techniczny Wojsk Lotniczych. 
Systems) mają one pozwolić na [7]:

- bieżące monitorowanie naprężeń występujących w elementach strukturalnych statków powietrznych;

- detekcję powstałych uszkodzeń;

- monitorowanie wzrostu uszkodzeń;

- prognozę zapasu bezpieczeństwa konstrukcji.

Oprócz zwiększenia poziomu bezpieczeństwa szacuje się, że wprowadzenie systemów SHM, wspomagających programy badań nieniszczących poprzez wstępną identyfikację i oszacowanie wielkości uszkodzeń, pozwoliłoby na zaoszczędzenie do $50 \%$ kosztów związanych z przeglądami, w zależności od rodzaju statku powietrznego [3].

Wprowadzenie systemów SHM jest szczególnie ważne w przypadku materiałów kompozytowych. To właśnie w tym przypadku ogniskują się aspekty bezpieczeństwa oraz te natury ekonomicznej. Materiały kompozytowe są narażone na uszkodzenia pochodzące od udarów, powstające w sposób losowy, ponadto mechanizmy ich zmęczeniowej degradacji nie są tak dobrze poznane jak w przypadku metali, zatem wyznaczenie bezpiecznego okresu pomiędzy kolejnymi przeglądami struktury obarczone jest dodatkowym ryzykiem. Uderzenia, nawet te o niskiej energii mogą spowodować pękanie osnowy i rozwarstwienia laminatu kompozytowego (rys. 1) oraz znaczne osłabienie wytrzymałości. Uszkodzenia tego typu są niewidoczne lub słabo widoczne (ang. Barely Visible Impact Damages - BVID) na powierzchni elementu w związku z czym ich detekcja jest czasochłonna i wymaga stosowania specjalistycznych urządzeń zwiększając koszty utrzymania. Prowadzone w ramach projektu badania ukierunkowane będą w dużej części na opracowanie metod detekcji uszkodzeń BVID.

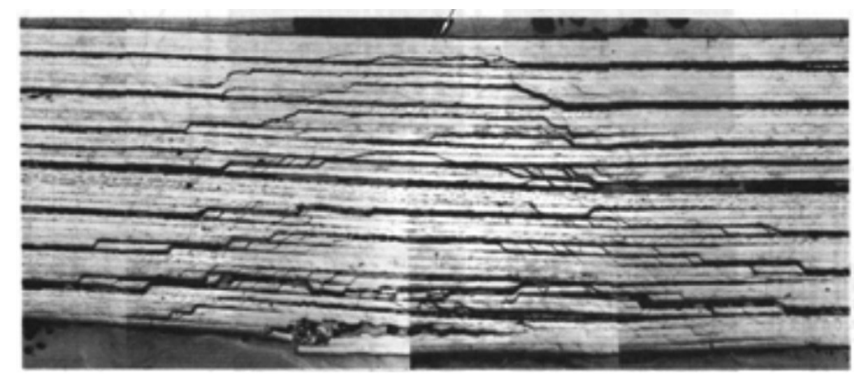

Rys. 1. Uszkodzenie BVID w kompozycie CFRP [8]

Fig. 1. BVID of CFRP composite structure [8]

\section{Monitorowanie stanu konstrukcji lotniczych z wykorzystaniem sieci przetworników pzt}

Jedną z idei budowy systemów bieżącego monitorowania konstrukcji jest wykorzystanie mechanicznych właściwości materiałów użytych przy produkcji danego elementu statku powietrznego. Opiera się ona na rejestracji przebiegu fal mechanicznych wzbudzonych w danym ośrodku przez sieć przetworników piezoelektrycznych (PZT), generujących $\mathrm{w}$ danej konstrukcji fale sprężyste. Propagacja fal sprężystych w elementach cienkościennych o małej krzywiźnie, charakterystycznych dla konstrukcji lotniczych, jest zjawiskiem stosunkowo złożonym. Dla danej częstotliwości sygnału wymuszającego współistnieć mogą różne mody falowe o różnych prędkościach propagacji, które zależą m.in. od grubości danego elementu $d$, częstotliwości wymuszenia $f$, oraz modułów sprężystości danego materiału. Mody te mogą ulegać rozproszeniu i konwersji na naturalnych elementach konstrukcji, np. szwy nitowe, krawędzie, utrudniając wizualną ocenę sygnałów stosowaną w przypadku klasycznych metod badań nieniszczących. Rozwarstwienia elementów kompozytowych powstałe wskutek uderzeń, poprzez pęknięcia poszczególnych warstw wpływają na lokalną zmianę sztywności danego elementu oraz grubości materiału, przez który propagują fale sprężyste. Zmiana prędkości propagacji modów falowych w obszarze uszkodzenia spowodować może przesunięcie paczek falowych rejestrowanego sygnału, zależnie od powierzchni uszkodzenia i redystrybucję energii fali. Jednym z narzędzi wspomagających ocenę wspomnianych przesunięć jest analiza czasowo - częstotliwościowa z wykorzystaniem krótko-czasowej transformaty Fouriera (STFT). Krótko-czasowa transformata Fouriera sygnału (inaczej spektrogram), dana jest następująco:

$$
\operatorname{STFT}(f)(t, \omega)=\frac{1}{\sqrt{2 \pi}} \int f(\tau) w(t-\tau) e^{-i \omega \tau} d \tau
$$

gdzie funkcja $w(t)$ jest tzw. oknem modulującym analizowany sygnał, np. krzywą Gaussa. W krótko-czasowej analizie Fourierowskiej otrzymać można informację o dekompozycji sygnału na poszczególne częstotliwości w kolejnych przedziałach czasu. Pozwala to na filtrację sygnału nie tylko w dziedzinie częstotliwości, lecz również na separację modów falowych dla tych samych częstotliwości centralnych, różniących się prędkością propagacji w badanym elemencie. Na poniższych wykresach (rys. 2 i 3) przedstawione są przykładowe sygnały zarejestrowane dla dwóch stanów badanego elementu kompozytowego. Widoczne jest rozseparowanie rejestrowanych paczek falowych wskutek lokalnej zmiany prędkości propagacji poszczególnych modów fal sprężystych.
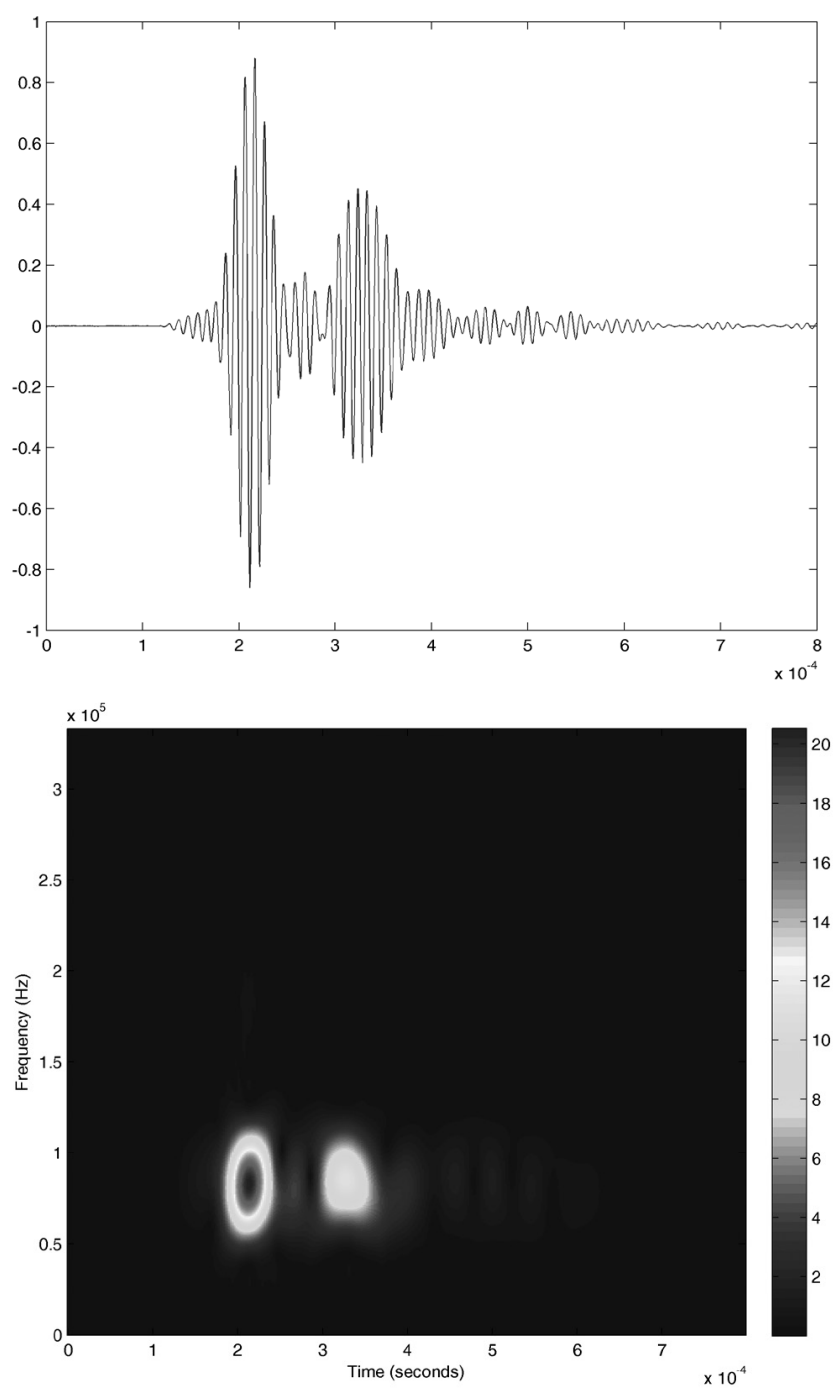

Rys. 2. Przykład sygnału odniesienia oraz jego krótko-czasowej transformaty Fouriera

Fig. 2. An example of baseline signal and its short-time Fourier transform 

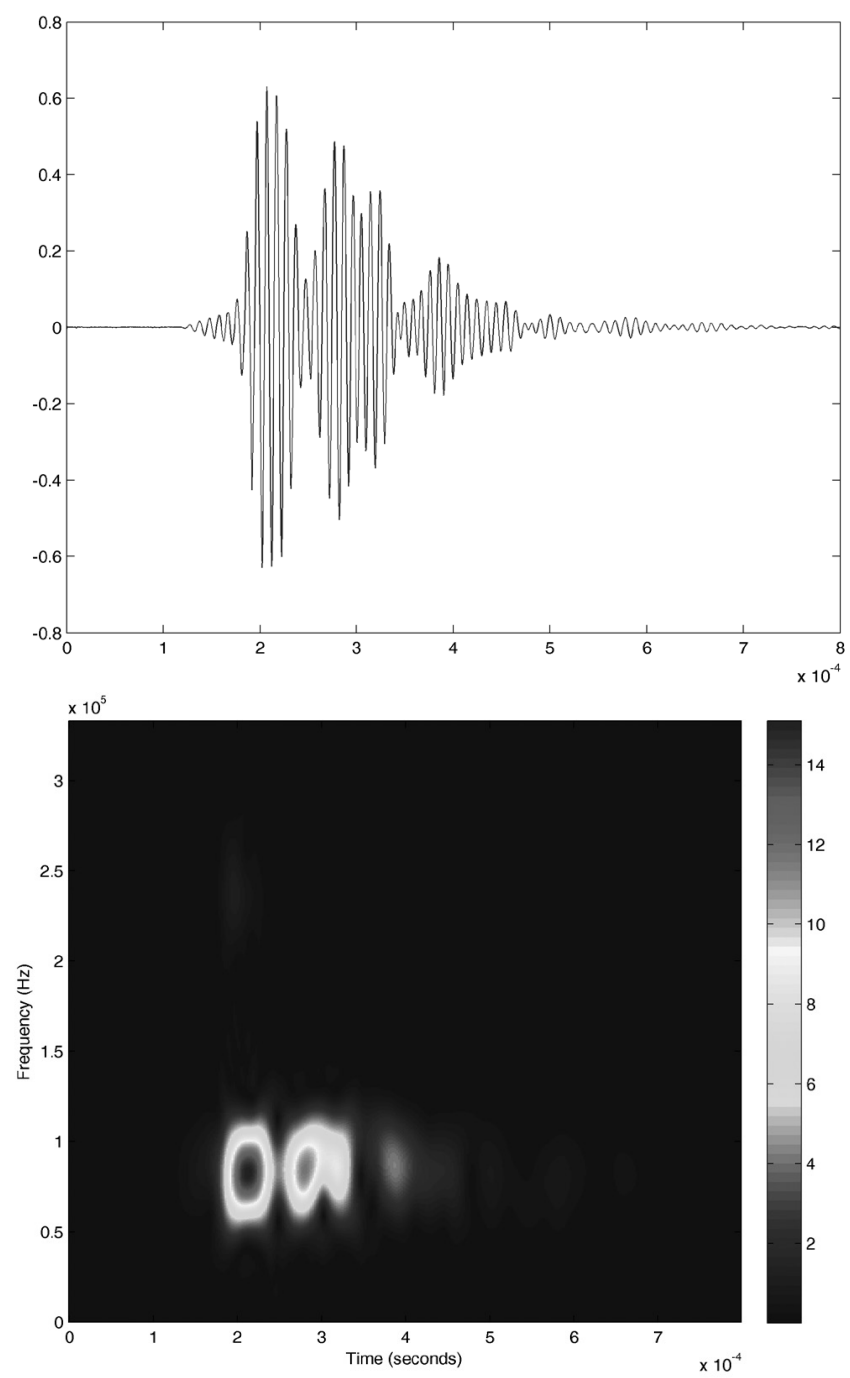

Rys. 3. Przykład sygnału zarejestrowanego dla próbki z rozwarstwieniami oraz jego krótkoczasowej transformaty Fouriera

Fig. 3. An example of signal obtained for damaged specimen and short-time Fourier transform of the signal

Automatycznego wnioskowania o stanie badanego obiektu dokonuje się zwykle na podstawie uproszczonych charakterystyk rejestrowanego sygnału, tzw. wskaźników uszkodzeń (ang. damage indices). Oznaczając przez $f_{g s}$ sygnał wygenerowany przez generator $g$ i zarejestrowany przez sensor $s$ dla danego stanu struktury, $f_{g s}{ }^{{ }^{2 n v}}$ jego obwiednię oraz przez $f_{g s, b}, f_{g s, b}^{\text {env }}$ odpowiadający sygnał odniesienia wraz z obwiednią, przykładowe wykorzystywane w literaturze wskaźniki uszkodzeń dane są następująco:

- charakterystyka $\mathrm{L}^{1} \quad L^{1}(g, s)=\frac{\int\left|f_{g s}\right| d t}{\int\left|f_{g s, b}\right| d t}$

$L_{e}^{1}(g, s)=\frac{\int f_{g s}^{e n v} d t}{\int f_{g s, b}^{e n v} d t}$

- charakterystyka L $L^{2} L^{2}(g, s)=\frac{\int\left(f_{g s}\right)^{2} d t}{\int\left(f_{g s, b}\right)^{2} d t}$

$$
L_{e}^{2}(g, s)=\frac{\int\left(f_{g s}^{e n v}\right)^{2} d t}{\int\left(f_{g s, b}^{e n v}\right)^{2} d t}
$$

- korelacja

$$
\operatorname{cor}(g, s)=\frac{\int f_{g s} f_{g s, b} d t-\int f_{g s} d t \int f_{g s, b} d t}{\sqrt{\int\left(f_{g s}\right)^{2} d t-\left(\int f_{g s} d t\right)^{2}} \sqrt{\int\left(f_{g s, b}\right)^{2} d t-\left(\int f_{g s, b} d t\right)^{2}}}
$$

Powyższe wskaźniki uszkodzeń są wrażliwe na zmiany sygnału związane z przesunięciami poszczególnych paczek falowych sygnału związane z rozwarstwieniami znajdującymi się na drodze propagacji sygnału. W celu zmniejszenia zależności wskazań systemu od lokalizacji uszkodzenia proponowane jest również wykorzystanie tzw. uśrednionych wskaźników uszkodzeń [9].

$$
A D I=\frac{1}{n(n-1)} \sum_{\substack{g, s: \\ g \neq s}} D I(g, s),
$$

gdzie $n$ jest liczbą sensorów w danej komórce sieci, zaś $D I(g, s)$ oznacza wybrany wskaźnik uszkodzeń. Uśrednione wskaźniki uszkodzeń są niezmiennicze ze względu na permutacje czujników i mogą być wykorzystane w statystycznych modelach klasyfikacyjnych i regresji.

\section{Wyniki monitorowania stanu konstrukcji dla panelu kompozytowego $z$ wbudowanymi czujnikami piezoelektrycznymi}

W celu walidacji opracowanych metod wykrywania uszkodzeń zaprojektowano i wykonano tzw. demonstrator „inteligentej” konstrukcji kompozytowej z czujnikami piezoelektrycznymi zabudowanymi w strukturze (pomiędzy warstwami i na strukturze). Demonstrator technologii wykonano w technologii pre-preg z wykorzystaniem kompozytu szklanego. Proces technologiczny utwardzania elementów przeprowadzono w autoklawie. Demonstrator wykonano z 16 warstw materiału - pre-pregu szklanego HCS2401-015. Do struktury pełniącej rolę poszycia przymocowano metodą klejenia 8-warstwowe podłużnice omegowe wykonane $\mathrm{z}$ tego samego materiału.

Przed wygrzaniem elementów demonstratora, specjalnie przygotowany zestaw czujników PZT w węzłach po 4 czujniki został ułożony w środkowej warstwie struktury kompozytowej (rys. 4).

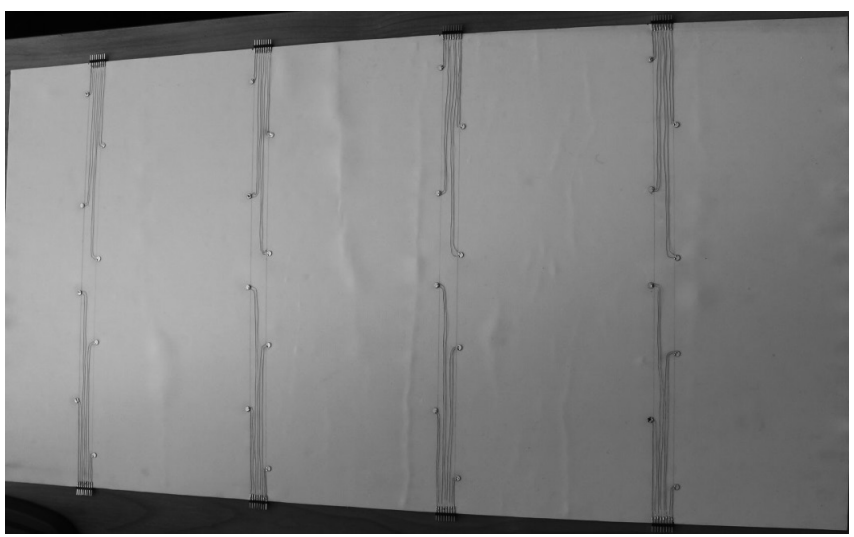

Rys. 4. Sieć czujników PZT w strukturze demonstratora

Fig. 4. PZT network embedded in the structure of a composite specimen

W celu sprawdzenia różnych rodzajów defektów przy pomocy wykonanego demonstratora, przygotowane podłużnice zostały przymocowane do głównego elementu w różny sposób, umożliwiające symulowanie wad produkcyjnych (np. wtrącenia materiału) oraz uszkodzeń eksploatacyjnych np. odklejenie kształtowników od poszycia. Takie podejście jest celowe i umożliwia weryfikację algorytmów rozpoznania i klasyfikacji uszkodzenia oraz możliwości śledzenia w czasie jego rozwoju.

Demonstrator poddano testom udarowym w celu weryfikacji możliwości wykrywania i lokalizowania uszkodzeń oraz kwantyfikacji wielkości energii z wykorzystaniem geometrii zaprojektowanej sieci czujników i metod analizy sygnałów.

Dla sieci wbudowanej w strukturę demonstratora dokonano pomiarów sygnału dla następujących parametrów:

- częstotliwość wymuszenia: 150, 200, 250, 300 kHz; 
- długość wymuszenia: 3 lub 8 okresów;

- modulacja sygnału sterującego: okno Hamminga.

W celu wizualizacji uszkodzenia wyznaczono znormalizowaną postać funkcji intensywności uszkodzeń w postaci (rys. 7):

$$
I(p)=\frac{1}{N(p)} \sum_{g \rightarrow s} D I(g, s) R_{g s}(p),
$$

gdzie $D I(g, s)$ jest wybranym wskaźnikiem uszkodzeń, Rgs opisuje obszar efektywnego monitorowania struktury dla danej pary przetworników g,s, zaś $N$ jest pewną funkcją charakteryzującą geometrię sieci przetworników.

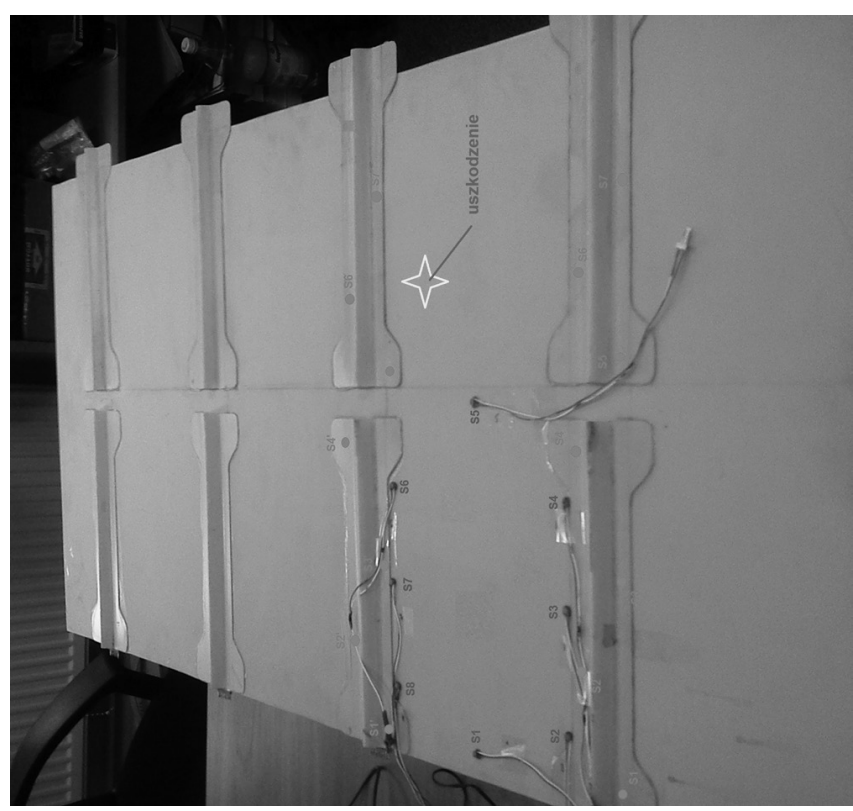

Rys. 5. Widok demonstratora z układem czujników i lokalizacją udaru Fig. 5. General view of the specimen with deployed PZT network and true localization of impact damage

Po zrealizowanych badaniach ultradźwiękowych wykonano ultradźwiękowe badania nieniszczące w celu weryfikacji wskazań uzyskanych przez system czujników pomiarowych. Badania ultradźwiękowe umożliwiły wymiarowanie uszkodzenia w zależności od uszkodzenia co pozwoliło na korelowanie uzyskanych wyników z sygnałem pomiarowym rejestrowanym przez sieć czujników w fazie testowej a w dalszej części eksperymentu na weryfikację działania systemu. W chwili obecnej trwają intensywne prace eksperymentalne polegające na symulowaniu zachowań struktury od obciążeń eksploatacyjnych i monitorowaniu integralności konstrukcji. Eksperyment ten jest weryfikowany z wykorzystaniem metod badań nieniszczących. Uzyskane dane będą w dalszej kolejności wykorzystywane do optymalizacji algorytmów analizujących sygnał jak również metodologii projektowania struktur kompozytowych oraz sieci czujników.

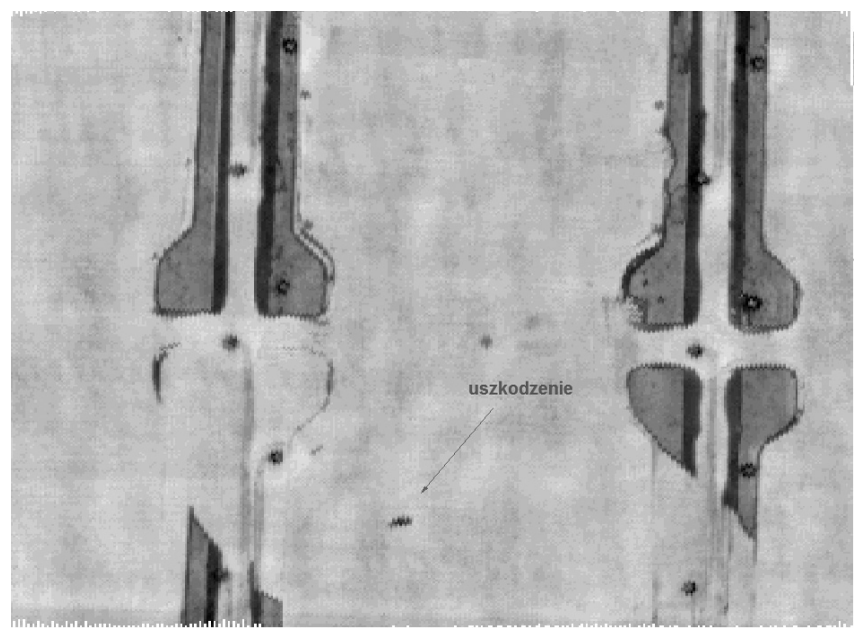

Rys. 6. Zobrazowanie badań UT

Fig. 6. Ultrasonic scan of the structure

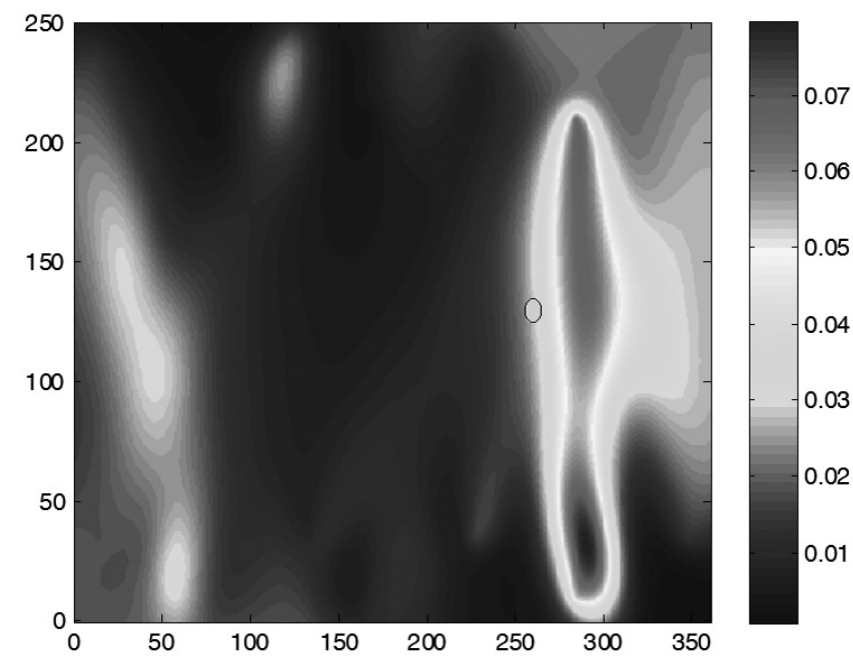

Rys. 7. Funkcja intensywności uszkodzeń z zaznaczeniem lokalizacji uszkodzenia

Fig. 7. Damage intensity function with indication of true damage localization

\section{Podsumowanie}

W artykule przedstawiono przykład struktury kompozytowej z wbudowanymi przetwornikami PZT, umożliwiającymi bieżącą diagnostykę jej stanu. W pracy zaprezentowano wybrane algorytmy analizy sygnału rejestrowanego przez przetworniki PZT. Dzięki wykorzystaniu zaproponowanych rozwiązań przetworniki PZT wbudowane w strukturę kompozytu umożliwiają min. detekcję i lokalizację udarowych uszkodzeń konstrukcji, co potwierdzono w badaniach laboratoryjnych. Dalsze prace będą związane z optymalizacją kształtu budowy sieci czujników oraz metod analizy sygnału.

\section{Literatura}

[1] Y. Kim, S. Sheehy, D. Lenhardt: A survey of Aircraft Structural-Life Management Programs in the U.S. Navy, the Canadian Forces, and the U.S. Air Force, RAND Corporation monograph series, 2006.

[2] United States Department of Defence. MIL-HDBK-1823A: Nondestructive evaluation system: reliability assessment, 2009.

[3] C. Boller, W.J Staszewski: Aircraft structural health and usage monitoring. John Wiley and Sons, Ltd, 2004.

[4] V. Giurgiutiu: Structural health monitoring: with piezoelectric wafer active sensors. Academic Press, 2007.

[5] Z. Su, L. Ye: Identification of damage using lamb waves: from fundamentals to applications. Springer, 2009.
[6] D. Adams: Health Monitoring of Structural Materials and Components: Methods with Applications. John Wiley and Sons, Ltd, 2007.

[7] D. Roach: Industry survey of structural health monitoring technology and usage. Sandia National Laboratories, 2012.

[8] L. Ilcewicz: CS\&TA Federal Aviation Administration, 2006.

[9] M. Dziendzikowski, K. Dragan, A. Kurnyta, S. Klysz, A. Leski: Damage Size Estimation of the Aircraft Structure with use of Embedded Sensor Network Generating Elastic Waves. Key Engineering Materials, 598: 57-62, 2014. 